\title{
Electrocardiography in Rats: a Comparison to Human
}

\author{
P. KONOPELSKI ${ }^{1}$, M. UFNAL ${ }^{1}$ \\ ${ }^{1}$ Department of Experimental Physiology and Pathophysiology, Laboratory of Centre for Preclinical \\ Research, Medical University of Warsaw, Warsaw, Poland
}

Received December 3, 2015

Accepted March 18, 2016

On-line July 15, 2016

\begin{abstract}
Summary
Electrocardiography (ECG) in rats is a widely applied experimental method in basic cardiovascular research. The technique of ECG recordings is simple; however, the interpretation of electrocardiographic parameters is challenging. This is because the analysis may be biased by experimental settings, such as the type of anesthesia, the strain or age of animals. Here, we aimed to review electrocardiographic parameters in rats, their normal range, as well as the effect of experimental settings on the parameters variation. Furthermore, differences and similarities between rat and human ECG are discussed in the context of translational cardiovascular research.
\end{abstract}

\section{Key words}

Rats • Cardiovascular system • Cardiac electrophysiology • QT • Interval • QRS

\section{Corresponding author}

M. Ufnal, Department of Experimental Physiology and Pathophysiology, Medical University of Warsaw, Banacha 1B, 02-097 Warsaw, Poland. Phone/Fax: +48 221166 195. E-mail: mufnal@wum.edu.pl

\section{Introduction}

Electrocardiography (ECG) in humans was introduced in 1903 by Willem Einthoven. Since then, it has become one of the most widespread diagnostic tools in clinical medicine. ECG recording reflects the electrical activity of the heart and may provide important insights into functional and structural characteristics of the myocardium. The physiological and pathological criteria of ECG recordings have been thoroughly described in multiple handbooks and research papers (Hall et al. 2011, Wagner et al. 2009).

Despite some differences, such as the lack of Q wave in most leads (Driscoll 1981, Farraj et al. 2011), there are essential similarities between rat and human ECG (Sambhi and White 1960), (Fig. 1). Therefore, ECG in rats has been exploited in basic cardiovascular research dealing with the heart's performance under physiological conditions and in animal models of cardiovascular diseases.

Although the technique of ECG recordings is rather simple, the interpretation of the acquired data is challenging. First, in contrast to humans, the criteria of reference ECG parameters in rats have not been established. Second, there are significant differences in ECG parameters between the experimental studies in rats. The latter seems to result from different experimental settings, such as the age and strain of animals and the type of anesthesia used (Table 1,2).

Here, we aimed to review electrocardiographic parameters in rats, their range, as well as the effect of experimental settings on the parameters variation. The review is confined to Sprague Dawley (SD) and Wistar rats, as these are the two strains most commonly used in cardiovascular experiments.

\section{Major ECG techniques}

There are several invasive and non-invasive techniques that allow 1 to 12 channel ECG recordings in laboratory animals. Most studies use a limb lead II that is 
Table 1. Comparison of ECG parameters between Sprague-Dawley and Wistar rats.

\begin{tabular}{lllllll}
\hline & HR (bpm) & PR (ms) & QRS (ms) & QT (ms) & QTc (ms) & ST (ms) \\
\hline Sprague-Dawley & $239-508$ & $38-70$ & $12-22$ & $50-75.9$ & $119-141^{1}$ & $12.3-18.1$ \\
Wistar & $242-452$ & $39-78$ & $14-28$ & $57-95$ & $133-173^{2}$ & $9.5-14.8$ \\
\hline
\end{tabular}

Heart rate in beats per minute (bpm), other parameters in milliseconds (ms). ${ }^{1}$ - QTc calculated by Fridericia formula, ${ }^{2}$ - QTc calculated by Bazett's formula.

Table 2. The effect of anesthetics on ECG parameters in Sprague-Dawley and Wistar rats.

\begin{tabular}{lllll}
\hline Strain/anesthetics & HR (bpm) & PR (ms) & QRS (ms) & QT (ms) \\
\hline $\begin{array}{l}\text { Sprague-Dawley } \\
\text { Light ether }\end{array}$ & & & $50-70$ \\
Ketamine and xylazine & $340-508$ & $48-70$ & $11.3-16.1$ & - \\
Urethane & $239-272$ & $56-66$ & $12-15.7$ & $60.6-62.5$ \\
Pentobarbital & $417-451$ & $48-56$ & $18.5-21.5$ & $63-74$ \\
Wistar & $387-446$ & $38-44$ & $20-22$ & $57-75$ \\
Light ether & & & & $75-95$ \\
Ketamine and xylazine & $290-378$ & $52-78$ & $18-28$ & - \\
Urethane & $242-336$ & $39-57$ & $17-25$ & $69-76$ \\
Pentobarbital & $357-452$ & $49-58$ & $18-19.6$ & \\
\hline
\end{tabular}

Heart rate in beats per minute (bpm), other parameters in milliseconds (ms).

sufficient for the general analysis of ECG parameters in rodents (Farraj et al. 2011, Buschmann et al. 1980), whereas precordial leads are used to localize pathological processes such as myocardial ischemia (Krenek et al. 2009).

\section{Invasive methods}

Surface ECG recording is the most commonly used technique in anesthetised rats. To obtain a limb leads recording, the electrodes are placed under the skin of left and right forepaws and the tail. Additionally, unipolar leads can be positioned anteriorly at the midsternum (Normann et al. 1961). Advantages of this method include its simplicity, high quality of collected data and repeatability, while its main drawback is that measurements may be confounded by anesthetics.

An ECG recording technique that escapes the effect of anesthesia is telemetry. Telemetry transmitters are implanted subcutaneously in the interscapular region or in the abdominal cavity, whereas electrodes connected to the transmitters are placed subcutaneously on the dorsal surface of the xiphoid process and anterior mediastinum. Data from transmitters are gathered wirelessly by a receiver positioned outside the rat cage (Sgoifo et al. 1998). This enables measurements in freely moving rats for several weeks. The method provides data that are free of anesthesia and stress-induced artefacts (Braga et al. 2011). However, the quality of the recordings may be compromised by movement of animals, displacement of the electrodes or inflammation at the site of electrode implantation.

An in vitro method for recording the electric activity from the isolated heart is the method introduced by the Langendorff in 1898. The heart is extracted form terminally anesthetized rat and placed into a perfusion apparatus. The heart is perfused with a perfusion fluid under physiological pressures, keeping the electromechanical work of the myocardium, functions of the valves and coronary blood flow. Advantages of this technique include a precise recording of the origin and amplitude of electrical events as well as possibility of concomitant evaluation of the coronary blood flow and contractility of the myocardium. The advantages, however, are limited by the fact that the isolated heart is 
separated from physiological effects of humoral and nervous control (Skrzypiec-Spring 2007, Döring 1989).

\section{The effect of anesthesia on ECG}

The choice of anesthesia may significantly affect the results of experiments, as anesthetics differ in their effects on cardiomyocytes and conducting system of the heart. For example, it has been found that inhalation anesthetics may have an arrhythmogenic potential. Halotane, isoflurane, and enflurane have been shown to block $\mathrm{Ca}^{2+}$ channels and $\mathrm{Na}^{+} / \mathrm{Ca}^{2+}$ exchange in cardiomyocytes (Mayo and Jamali 1999). Cardiotoxic effects have also been reported after parenteral anesthesia. Urethane anesthetised rats show a significant depression of HR, whereas the effect is not observed in rats treated with pentobarbital and thiopental. Pentobarbital, however, was found to evoke ventricular arrhythmias. In contrast, thiopental was found to possess antiarrhythmic activity (Zorniak et al. 2010). Ketamine, another commonly used anesthetic drug, apart from its anti-NMDA activity, interacts with cardiac voltagesensitive $\mathrm{Ca}^{2+}$ channels that may also significantly affect the electrical activity of cardiomyocytes (Hirota and Lambert 1996, Baum and Tecson 1991), (Table 2).

\section{Non-invasive systems}

An example of a non-invasive method of ECG recordings is dressing rats in a cotton jacket with two electrodes attached to its inner surface. Before wearing the coat, rats' skin must be shaved in anterior thoracic region. Measurements are performed in conscious rats placed in plastic restrainers (Pereira-Junior et al. 2010). Advantages of this technique include non-invasiveness, measurements in conscious animals and a significantly lower cost in comparison to telemetry. Nevertheless, restraint-stress and difficulties with placing the electrodes in the same position in different rats are significant limitations of the method.

Another method is a non-invasive ECG recording in conscious rats placed in a restrainer also referred as a tunnel. In this technique paws of the rat are placed on ECG sensors embedded in the tunnel floor. After short adaptation period up to 6 lead ECG, lasting 30-60 min, can be obtained (Mongue-Din et al. 2007).

\section{Electrocardiographic parameters}

An action potential in the heart is generated in sinoatrial node and subsequently conducted through atrioventricular node, His bundle, His bundle branches and Purkinje fibres, finally reaching ventricular cardiomyocytes. A typical ECG tracing mirrors the repeating cycle of three major electrical events, including atrial depolarization ( $\mathrm{P}$ wave), ventricular depolarization (QRS complex) and ventricular repolarization ( $\mathrm{T}$ wave), (Fig. 1).

\section{Heart rate and RR interval}

Heart rate (HR) represents the number of heart contractions over a specific period of time, most commonly 1 min (beats per minute, bpm). RR interval is the time between the consecutive $\mathrm{R}$ wave peaks. Under physiological conditions, HR can be calculated from RR interval according to the following formula: $H R=60 /(R-R$ interval in seconds). In humans HR can also be calculated by measuring the time between the consecutive $\mathrm{Q}$ waves, while in rats HR is calculated using RR intervals only. This is because rat ECG lacks the Q wave in most leads and/or the Q wave may be difficult to locate, especially in noisy and low amplitude ECG.

Mammals have a wide distribution of resting RR interval. For an adult human, resting RR interval ranges from $0.6-1 \mathrm{~s} \quad(\mathrm{HR} \approx 60-100 \mathrm{bpm}$ ) (Hall et al. 2011), whereas for matured rats $\mathrm{RR}$ interval is $118-251 \mathrm{~ms}$ (HR $\approx 239-508$ ), (Table 1). In rats HR depends on age, and it has been found to increase during the first 4 weeks after the birth (Malfatto et al. 1990, Dickhout and Lee 1998). In newborn restrained Wistar rats, HR is $298-306$ bpm and then reaches steady values of $429-473 \mathrm{bpm}$ just before puberty (Malfatto et al. 1990). Therefore, in contrast to humans, there seems to be no clear negative correlation between HR and aging before puberty in rats. On the other hand, a decrease in HR with aging was found in postpubertal Wistar rats using chronic telemetry recording (Sgoifo et al. 1998).

HR seems to be strongly affected by the type of anesthesia used. In SD rats anesthetised with ketamine and xylazine mixture, light ether, urethane and pentobarbital heart rate was found to be $239-272 \mathrm{bpm}$ (Regan et al. 2005, Regan et al. 2007), 340-508 bpm (Normann et al. 1961), 417-451 bpm (Lin et al. 1997), and 387-446 bpm (Sugiyama et al. 2005), respectively. $\mathrm{HR}$ in Wistar rats was reported as $242-336 \mathrm{bpm}$ under ketamine and xylazine anesthesia (Miranda et al. 2007), 290-378 bpm under light ether anesthesia (Fraser et al. 1967), $\quad 357-452 \mathrm{bpm}$ under urethane anesthesia (Buschmann et al. 1980), and $334-349 \mathrm{bpm}$ in rats anesthetised with pentobarbital (Ahmad et al. 2015). 
The P wave

In ECG recording, the $\mathrm{P}$ wave reflects depolarization of the atria. In both humans and rats, physiological sinus rhythm is characterized by a positive deflection of the $\mathrm{P}$ wave in limb lead II, a negative deflection of the $\mathrm{P}$ wave in lead aVR, and the presence of QRS complex after every $P$ wave. The lack of the $P$ wave or its altered shape is present in various cardiac arrhythmias, the most common of which is atrial fibrillation.

Similarly to humans, atrial fibrillation in rats is characterized by the lack of the $\mathrm{P}$ wave (Haugan et al. 2004, Nattel et al. 2005). Although in humans the analysis of the length and shape of the $\mathrm{P}$ wave brings clinically important insights, in rats there is not enough experimental data to conclude form alterations in the $P$ wave shape and length. However, Milliez and collaborators reported that the prolongation of the $\mathrm{P}$ wave may be associated with increased susceptibility to supraventricular arrhythmias in Wistar rats after myocardial infarction (Milliez et al. 2005).

\section{PR interval}

The PR interval, also referred to as the PQ interval Q wave is not always present, reflects the propagation of depolarization from atria to the heart ventricles (Hoffman et al. 1960, Beinfield and Lehr 1968). The PR interval is determined by measuring the time from the beginning of the $\mathrm{P}$ wave until the beginning of the QRS or RS complex. The analysis of the length of PR interval is crucial in the diagnosis of atrioventricular blocks.

The PR interval in SD rats ranges from 38 to $70 \mathrm{~ms}$ and its length seems to be significantly affected by the type of anesthesia. Namely, the PR interval was reported to be $38-44 \mathrm{~ms}$ in pentobarbital anesthesia (Sugiyama et al. 2005), 48-70 ms in light ether anesthesia (Normann et al. 1961), 48-56 ms in urethane anesthesia (Lin et al. 1997), 56-66 ms in ketamine combined with xylazine anesthesia (Regan et al. 2005, Regan et al. 2007), and 52-60 ms in isoflurane anesthesia (Hamdy and Brocks 2009).

In Wistar rats, PR interval was found to be 39 to $78 \mathrm{~ms}$, and its length also varied dependent on the type of anesthesia. Rats anesthetized with a mixture of ketamine and xylazine had the shortest duration of the parameter (39-57 ms) (Miranda et al. 2007). A longer PR interval was reported in rats under urethane (49-58 ms) (Buschmann et al. 1980) and ether anesthesia (52-78 ms) (Fraser et al. 1967).

\section{QRS complex}

QRS complex is located between Q and $\mathrm{S}$ waves. Its duration shows the time of propagation of depolarization through the ventricles. The analysis of the length of QRS complexes provides important data on electrical activity of the heart. QRS narrowing can be seen in supraventricular arrhythmias, whereas wide QRS complexes reflect ventricular rhythms as well as disturbances of intraventricular conduction that can be seen in right and left bundle branch blocks, heart failure and myocardial ischemia. Wide QRS complexes were found after treating rats with several drugs, for example doxorubicin (Kelishomi et al. 2008), disopyramide (Król et al. 2015), and azithromycin (Atli et al. 2015).

Since Q wave is usually not detectable in rats, RS or Rs complexes are evaluated in rat ECG. Duration of RS complexes in SD rats under a light ether anesthesia is 11.3-16.1 ms (Kelishomi et al. 2008), 12-15.7 ms in rats anesthetized with ketamine and xylazine (Regan et al. 2005), 20-22 $\mathrm{ms}$ in rats undergoing pentobarbital anesthesia (Sugiyama et al. 2005), and 18.5-21.5 in rats under urethane anesthesia (Badole et al. 2014).

QRS length in Wistar rats was found to be 14-16 ms (Buschmann et al.1980), 17-25 ms (Miranda et al. 2007), 18-19.6 ms (Ahmad et al. 2015), and 18-28 ms (Fraser et al. 1967) in rats anesthetized with urethane, ketamine combined with xylazine, pentobarbital and ether, respectively.

\section{ST segment}

ST segment represents the time when the ventricles are depolarized and is defined as the time from the end of QRS complex to the beginning of $\mathrm{T}$ wave. It is isoelectric and lasts approximately 80 to $120 \mathrm{~ms}$ in humans. The evaluation of the parameter is essential in the diagnosis of myocardial ischemia and myocardial infarction. Therefore, in humans the criteria of significant changes, i.e. a depression or elevation of ST segment, have been thoroughly described (Wagner et al. 2009). Alteration of ST segment may also occur in other conditions such as channelopathies e.g. Brugada syndrome, intraventricular conduction blocks, waterelectrolyte balance disturbances and others.

Studies in rats showed significant changes in ST segment in myocardial infarction (Chrastina et al. 2014) and in myocardial ischemia (Speechly-Dick et al. 1994), however, clear criteria of significant changes in ST segment have not been established. Some researchers evaluated the duration of ST in rats. In SD rats 
undergoing light ether anesthesia the duration of ST segment was reported to be 12.3-18.1 ms (Kelishomi et al. 2008), while in Wistar rats anesthetized with ether it was $9.58-14.8 \mathrm{~ms}$ (Dragojevic-Simic et al. 2004). However, the length of ST segment is of limited importance for ECG analysis. First, it is difficult to detect ST segment in rat ECG as the $\mathrm{T}$ wave often rises in continuity with the S wave (Sambhi and White 1960, Jensen et al. 1984) (Fig. 1). Second, the prolongation of ST segment lengthens QT (RT) intervals. Therefore, it is more convenient to analyse the two latter parameters rather than ST segment.

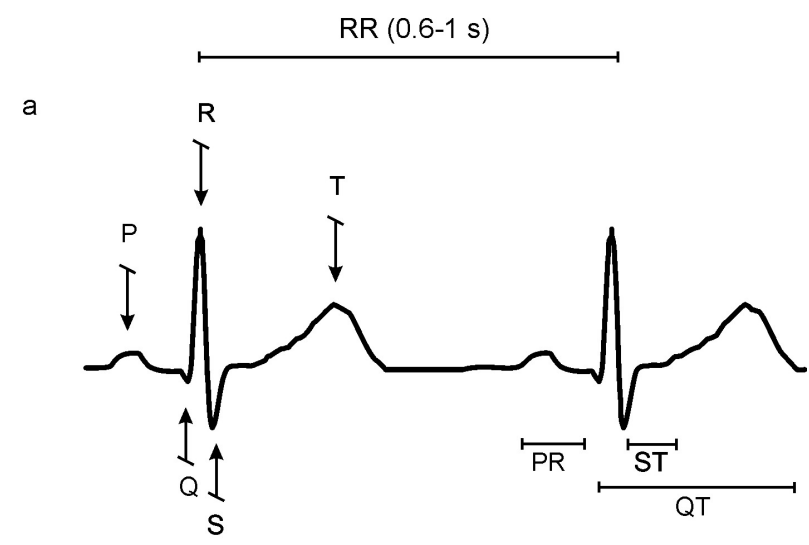

b

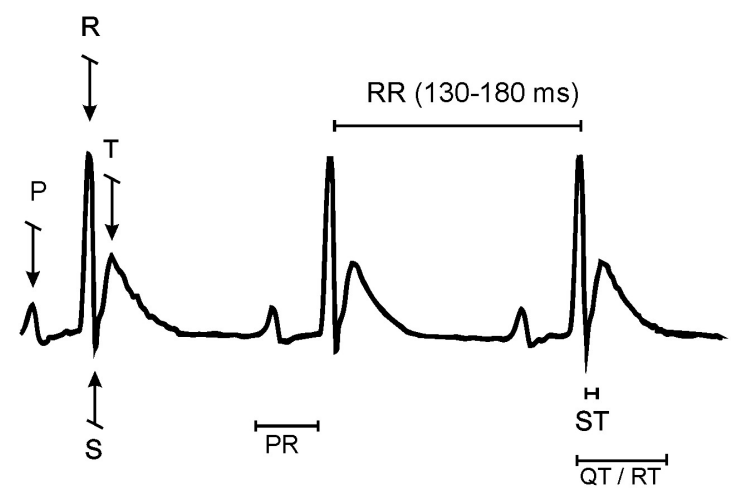

Fig. 1. Original recording of human (a) and Wistar rat (b) ECG, II limb lead. RR interval in humans in seconds, in rats in milliseconds. Q waves and ST segments in rats are difficult to detect.

Twave

$\mathrm{T}$ wave reflects repolarization of the ventricles.

The $\mathrm{T}$ wave has a positive deflection in the majority of leads including limb lead II. In humans, high voltage/peaking of $\mathrm{T}$ wave may be found in hyperkalaemia, in early phases of acute myocardial infarction and in patients with Long QT Syndrome. A decreased amplitude of the $\mathrm{T}$ wave may be present in hypokalaemia, whereas a negative deflection of the
$\mathrm{T}$ wave may result from myocardial infarction and pulmonary embolism.

Rat ECG shows the upright $\mathrm{T}$ wave in limb lead II. Inversion of the parameter in rat ECG was reported after injection of isoproterenol and myocardial infarction (Hill et al. 1960). Hypokalaemia in rats was found to produce prolongation and decrease in voltage of T wave (Akita et al. 1998).

\section{QT interval}

QT interval describes the time from the Q wave to the end of the $\mathrm{T}$ wave. In rats, this parameter is usually measured from the onset of Rs complex to the end of $\mathrm{T}$ wave, due to difficulties with detecting $\mathrm{Q}$ waves. QT interval represents the time of depolarization and repolarization of ventricular cardiomyocytes. Pathological duration of this parameter indicates disturbances in electrical activity of the heart due to an intrinsic heart disease or toxic effects of exogenous compounds. For example, QT interval may be prolonged by hypokalaemia, ischemia, myocardial infarction, channelopathies, including Long QT syndrome. Finally, multiple drugs may produce prolongation of QT interval leading to ventricular tachyarrhythmia, including torsade de pointes. Therefore, the prolonged QT interval is considered to be a useful indicator of drug cardiotoxicity (Hanada et al. 1999, Roden et al. 2004). Interestingly, sex-related differences have been observed in susceptibility to drug-induced arrhythmias in both humans and laboratory animals (Makkar et al. 1993, Liu et al. 1999).

A number of studies have shown that cardiotoxic drugs prolong QT interval in rodents, and ECG recording in rats has been used as a screening tool in cardiotoxicity studies (Hanada et al. 1999, Ohtani et al. 1996, Król et al. 2016). However, it needs to be stressed that the translation of the results of those studies to humans has limitations. This is because rats' hearts do not express the human Ether-à-go-go-Related Gene (hERG), whereas drugs cardiotoxicity is strongly associated with blocking of hERG-related potassium channels (De Bruin et al. 2005). However, the rats' hearts express a variant of Ether-à-go-go-Related Gene (rat ERG, also known as Kcnh2) (Matus et al. 2015), which may play a role in drug induced cardiotoxicity, but further research is needed to support this notion.

A prolonged QT interval in rats has also been found in hypokalaemia (Akita et al. 1998) and myocardial infarction (Mackiewicz et al. 2014). 
Furthermore, as with other ECG parameters, QT length seems to be affected by the type of anesthesia. In SD rats it was found to be $50-70 \mathrm{~ms}$ (mean $53.6 \mathrm{~ms}$ ) under light ether anesthesia (Normann et al. 1961), 60.6-62.5 ms under urethane anesthesia (Hanada et al. 1999), 63-74 ms under pentobarbital (Sugiyama et al. 2005), and 64.1-75.9 ms under isoflurane anesthesia (Hamdy and Brocks 2009).

In conscious Wistar rats QT length in telemetric recording was reported to be $69-71 \mathrm{~ms}$ (Baillard et al. 2000), 57-75 ms in rats under ether anesthesia (Fraser et al. 1967), $69-76 \mathrm{~ms}$ in rats under pentobarbital anesthesia (Ahmad et al. 2015), and 75-95 ms in rats under ketamine and xylazine anesthesia (Miranda et al. 2007).

\section{Corrected QT interval}

It is well-established that the length of QT interval in humans depends on HR. In general, an increase in HR shortens QT as the ratio of the lengths of systole and diastole increases. Therefore, a corrected QT interval (QTc) that takes into account changes in HR is often used as a more objective parameter of depolarization and repolarization of ventricles (FunckBrentano and Jaillon 1993, Ahnve 1985).

Although in rats HR is about 5-6 times higher than in humans, there is no consensus on whether there is a need to adjust QT to HR (Hayes et al. 1994, Kmecova and Klimas 2010). The majority of rat studies use one of several formulas to calculate QTc (Hamdy and Brocks 2009, Baillard et al. 2000).

One of the adjustments of QT to HR is the Bazett's formula, which was presented in 1920 after the analysis of ECG changes associated with exercises. The formula is based on dividing QT interval by the square root of RR-interval,

$$
\left(\frac{Q T}{\sqrt{R R}}\right),(\text { Bazett 1920). }
$$

Due to its simplicity, it is a very useful tool in both at the bedside and experimental research. However, it seems inappropriate for $\mathrm{HR}$ exceeding $100 \mathrm{bpm}$ (Molnar et al. 1996). In Wistar rats, QTc calculated according to Bazett's formula was reported to be 133-173 ms in ether-anesthetized rats (Fraser et al. 1967), and $152-156 \mathrm{~ms}$ in telemetry recordings in conscious rats
(Baillard et al. 2000).

Another method for calculating the QTc is Fridericia's formula, which is as follows: QT interval divided by cube-root of RR-interval,

$$
\left(\frac{Q T}{\sqrt[3]{R R}}\right)
$$

Some researchers suggest that this equation may be the preferable way of correcting the QT (Schwartz and Wolf 1978). QTc interval calculated by Fridericia's formula in isoflurane anesthetized Sprague-Dawley rats was found to be 119-141 ms (Funck-Brentano and Jaillon 1993).

The profound analysis of correlation between QTc and QT, dependent on HR, was performed by Kmecova and Klimas (2010). Their research suggest that QTe interval should be calculated according to adjusted Bazett's formula, namely

$$
\mathrm{QTc}=\frac{Q T}{\sqrt{\frac{R R}{f}}},
$$

where $\mathrm{f}$ is the normalization factor according to the basal $\mathrm{RR}$ duration in rats, that is $150 \mathrm{~ms}$ (Kmecova and Klimas 2010).

\section{Conflict of Interest}

There is no conflict of interest.

\section{Conclusions}

Rat electrocardiography is an important investigational tool in experimental cardiology. However, the interpretation of electrocardiographic parameters is problematic. In contrast to human studies, the criteria to distinguish significant from insignificant changes in ECG parameters in rats have not been established. This is due to a relatively small number of experimental studies, as well as significant variations in electrocardiographic parameters between the studies. The latter is likely caused by differences in rat strains and anesthetics used. Therefore, there is a need for more studies, preferably employing measurements in conscious rats. In the meanwhile, the interpretation of ECG in rats should always take into account the effect of experimental settings, especially anesthesia and the strain of rats. 


\section{References}

AHMAD A, SATTAR MZ, RATHORE HA, KHAN SA, LAZHARI MA, HASHMI F, ABDULLAH NA, JOHNS EJ: Impact of Isoprenaline and Caffeine on development of left ventricular hypertrophy and renal hemodynamic in Wistar Kyoto rats. Acta Pol Pharm 72: 1015-1026, 2015.

AHNVE S: Correction of the QT interval for heart rate: review of different formulas and the use of Bazett's formula in myocardial infarction. Am Heart J 109: 568-574, 1985.

AKITA M, KUWAHARA M, TSUBONE H, SUGANO S: ECG changes during furosemide-induced hypokalemia in the rat. $J$ Electrocardiol 31: 45-49, 1998.

ATLI O, ILGIN S, ALTUNTAS H, BURUKOGLU D: Evaluation of azithromycin induced cardiotoxicity in rats. Int $J$ Clin Exp Med 8: 3681-3690, 2015.

BADOLE SL, JANGAM GB, CHAUDHARI SM, GHULE AE, ZANWAR AA: L-glutamine supplementation prevents the development of experimental diabetic cardiomyopathy in streptozotocin-nicotinamide induced diabetic rats. PloS One 9: e92697, 2014.

BAILLARD C, MANSIER P, ENNEZAT PV, MANGIN L, MEDIGUE C, SWYNGHEDAUW B, CHEVALIER B: Converting enzyme inhibition normalizes QT interval in spontaneously hypertensive rats. Hypertension 36: 350-354, 2000.

BAUM VC, TECSON ME: Ketamine inhibits transsarcolemmal calcium entry in guinea pig myocardium: direct evidence by single cell voltage clamp. Anesth Analg 73: 804-807, 1991.

BAZETT HC: An analysis of the time-relations of electrocardiograms. Heart 7: 353-370, 1920.

BEINFIELD WH, LEHR D: PR interval of the rat electrocardiogram. Am J Physiol 214: 205-211, 1968.

BRAGA VA, BURMEISTER MA: Applications of telemetry in small laboratory animals for studying cardiovascular diseases. In: Modern Telemetry. KREJCAR O (ed.), InTech, Rijeka, 2011, pp 183-196.

BUSCHMANN G, SCHUMACHER W, BUDDEN R, KÜHL UG: Evaluation of the effect of dopamine and other catecholamines on the electrocardiogram and blood pressure of rats by means of on-line biosignal processing. J Cardiovasc Pharmacol 2: 777-795, 1980.

CHRASTINA A, POKREISZ P, SCHNITZER JE: Experimental model of transthoracic, vascular-targeted, photodynamically induced myocardial infarction. Am J Physiol Heart Circ Physiol 306: H270-H278, 2014.

DE BRUIN ML, PETTERSSON M, MEYBOOM RHB, HOES AW, LEUFKENS HGM: Anti-HERG activity and the risk of drug-induced arrhythmias and sudden death. Eur Heart J 26: 590-597, 2005.

DICKHOUT JG, LEE RM: Blood pressure and heart rate development in young spontaneously hypertensive rats. $A m \mathrm{~J}$ Physiol Heart Circ Physiol 274: H794-H800, 1998.

DÖRING HJ: The isolated perfused heart according to Langendorff technique--function--application. Physiol Bohemoslov 39: 481-504, 1989.

DRAGOJEVIC-SIMIC VM, DOBRIC SL, BOKONJIC DR, VUCINIC ZM, SINOVEC SM, JACEVIC VM, DOGOVIC NP: Amifostine protection against doxorubicin cardiotoxicity in rats. Anticancer Drugs 15 : 169-178, 2004.

DRISCOLL P: The normal rat electrocardiogram. In: The Rat Electrocardiogram in Pharmacology and Toxicology. BUDDEN R, DETWEILER DK, ZBINDEN G (eds), Pergamon Press, New York, 1981, pp 1-14.

FARRAJ AK, HAZARI MS, CASCIO WE: The utility of the small rodent electrocardiogram in toxicology. Toxicol Sci 121: 11-30, 2011.

FRASER RS, HARLEY C, WILEY T: Electrocardiogram in the normal rat. J Appl Physiol 23: 401-402, 1967.

FUNCK-BRENTANO C, JAILLON P: Rate-corrected QT interval: techniques and limitations. Am J Cardiol 72: 17B-22B, 1993.

HALL JE: Cardiac Arrhythmias and their electrocardiographic interpretation. In: Guyton and Hall Textbook of Medical Physiology. HALL JE, GUYTON AC, SCHMITT W (eds), Saunders, London, 2011, pp 143-153.

HAMDY DA, BROCKS DR: Experimental hyperlipidemia causes an increase in the electrocardiographic changes associated with amiodarone. J Cardiovasc Pharmacol 53: 1-8, 2009. 
HANADA E, OHTANI H, KOTAKI H, SAWADA Y, SATO H, IGA T: Pharmacodynamic analysis of the electrocardiographic interaction between disopyramide and erythromycin in rats. J Pharm Sci 88: 234-240, 1999.

HAUGAN K, LAM HR, KNUDSEN CB, PETERSEN JS: Atrial fibrillation in rats induced by rapid transesophageal atrial pacing during brief episodes of asphyxia: a new in vivo model. J Cardiovasc Pharmacol 44: 125-135, 2004.

HAYES E, PUGSLEY MK, PEN WP, ADAIKAN G, WALKER MJA: Relationship between QaT and RR intervals in rats, guinea pigs, rabbits, and primates. J Pharmacol Toxicol Methods 32: 201-207, 1994.

HILL R, HOWARD AN, GRESHAM GA: The electrocardiographic appearances of myocardial infarction in the rat. Br J Exp Pathol 41: 633-637, 1960.

HIROTA K, LAMBERT DG: Ketamine: Its mechanism(s) of action and unusual clinical uses. Br J Anesth 77: 441-444, 1996.

HOFFMAN BF, CRANEFIELD PF, STUCKEY JH, BAGDONAS AA, PIERA J: Electrical activity during the PR interval. Circ Res 8: 1200-1211, 1960.

JENSEN RA, ACTON EM, PETERS JH: Doxorubicin cardiotoxicity in the rat: comparison of electrocardiogram, transmembrane potential, and structural effects. J Cardiovasc Pharmacol 6: 186-200, 1984.

KELISHOMI RB, EJTEMAEEMEHR S, TAVANGAR SM, RAHIMIAN R, MOBARAKEH JI, DEHPOUR AR: Morphine is protective against doxorubicin-induced cardiotoxicity in rat. Toxicology 243: 96-104, 2008.

KMECOVA J, KLIMAS J: Heart rate correction of the QT duration in rats. Eur J Pharmacol 641: 187-192, 2010.

KRENEK P, KMECOVA J, KUCEROVA D, BAJUSZOVA Z, MUSIL P, GAZOVA A, OCHODNICKY P, KLIMAS J, KYSELOVIC J: Isoproterenol-induced heart failure in the rat is associated with nitric oxide-dependent functional alterations of cardiac function. Eur J Heart Fail 11: 140-146, 2009.

KRÓL M, UFNAL M, SZULCZYK B, PODSADNI P, DRAPAŁA A, TURŁO J, DAWIDOWSKI M: Characterization of Disopyramide derivative ADD424042 as a non-cardiotoxic neuronal sodium channel blocker with broadspectrum anticonvulsant activity in rodent seizure models. Eur J Pharm Sci 81: 42-51, 2016.

LIN MT, LIU HH, YANG YL: Involvement of interleukin-1 receptor mechanisms in development of arterial hypotension in rat heatstroke. Am J Physiol Heart Circ Physiol 273: H2072-H2077, 1997.

LIU XK, WANG W, EBERT SN, FRANZ MR, KATCHMAN A, WOOSLEY RL: Female gender is a risk factor for torsades de pointes in an in vitro animal model. J Cardiovasc Pharmacol 34: 287-294. 1999.

MACKIEWICZ U, GERGES JY, CHU S, DUDA M, DOBRZYNSKI H, LEWARTOWSKI B, MĄCZEWSKI M: Ivabradine protects against ventricular arrhythmias in acute myocardial infarction in the rat. J Cell Physiol 229: $813-823,2014$.

MAKKAR RR, FROMM BS, STEINMAN RT, MEISSNER MD, LEHMANN MH: Female gender as a risk factor for torsades de pointes associated with cardiovascular drugs. JAMA 270: 2590-2597, 1993.

MALFATTO G, ROSEN TS, STEINBERG SF, URSELL PC, SUN LS, DANIEL S, DANILO PJR, ROSEN MR: Sympathetic neural modulation of cardiac impulse initiation and repolarization in the newborn rat. Circ Res 66: 427-437, 1990.

MATUS M, KUCEROVA D, KRUZLIAK P, ADAMEOVA A, DOKA G, TURCEKOWA K, KMECOVA J, KYSELOVIC J, KRENEK P, KIRCHHEFER U, MUELLER FU, BOKNIK P, KLIMAS J: Upregulation of SERCA2a following short-term ACE inhibition (by enalaprilat) alters contractile performance and arrhythmogenicity of healthy myocardium in rat. Mol Cell Biochem 403: 199-208, 2015.

MAYO PR, JAMALI F: Methoxyflurane anesthesia augments the chronotropic and dromotropic effects of verapamil. J Pharm Pharmaceut Sci 2: 30-35, 1999.

MILLIEZ P, DEANGELIS N, RUCKER-MARTIN C, LEENHARDT A, VICAUT E, ROBIDEL E, BEAUFILS P, DELCAYRE C, HATEM SN: Spironolactone reduces fibrosis of dilated atria during heart failure in rats with myocardial infarction. Eur Heart J 26: 2193-2199, 2005.

MIRANDA A, COSTA-E-SOUSA RH, WERNECK-DE-CASTRO JP, MATTOS EC, OLIVARES EL, RIBEIRO VP, SILVA MG, GOLDENBERG RC, CAMPOS-DE-CARVALHO AC: Time course of echocardiographic and electrocardiographic parameters in myocardial infarct in rats. An Acad Bras Cienc 79: 639-648, 2007. 
MONGUE-DIN H, SALMON A, FISZMAN MY, FROMES Y: Non-invasive restrained ECG recording in conscious small rodents: a new tool for cardiac electrical activity investigation. Pflugers Arch 454: 165-171, 2007.

MOLNAR J, WEISS J, ZHANG F, ROSENTHAL JE: Evaluation of five QT correction formulas using a softwareassisted method of continuous QT measurement from 24-hour Holter recordings. Am J Cardiol 78: 920-926, 1996.

NATTEL S, SHIROSHITA-TAKESHITA A, BRUNDEL BJ, RIVARD L: Mechanisms of atrial fibrillation: lessons from animal models. Prog Cardiovasc Dis 48: 9-28, 2005.

NORMANN SJ, PRIEST RE, BENDITT EP: Electrocardiogram in the normal rat and its alteration with experimental coronary occlusion. Circ Res 9: 282-287, 1961.

OHTANI H, HANADA E, YAMAMOTO K, SAWADA Y, IGA T: Pharmacokinetic-pharmacodynamic analysis of the electrocardiographic effects of terfenadine and quinidine in rats. Biol Pharm Bull 19: 1189-1196, 1996.

PEREIRA-JUNIOR PP, MAROCOLO M, RODRIGUES FP, MEDEI E, NASCIMENTO JH: Noninvasive method for electrocardiogram recording in conscious rats: feasibility for heart rate variability analysis. An Acad Bras Cienc 82: 431-437, 2010.

REGAN CP, CRESSWELL HK, ZHANG R, LYNCH JJ: Novel method to assess cardiac electrophysiology in the rat: characterization of standard ion channel blockers. J Cardiovasc Pharmacol 46: 68-75, 2005.

REGAN CP, STUMP GL, WALLACE AA, ANDERSON KD, MCINTYRE CJ, LIVERTON NJ, LYNCH JR JJ: In vivo cardiac electrophysiologic and antiarrhythmic effects of an isoquinoline IKur blocker, ISQ-1, in rat, dog, and nonhuman primate. J Cardiovasc Pharmacol 49: 236-245, 2007.

RODEN DM: Drug-induced prolongation of the QT interval. N Engl J Med 350: 1013-1022, 2004.

SAMBHI MP, WHITE FN: The electrocardiogram of the normal and hypertensive rat. Circ Res 8: 129-134, 1960.

SCHWARTZ PJ, WOLF S: QT interval prolongation as predictor of sudden death in patients with myocardial infarction. Circulation 57: 1074-1077, 1978.

SGOIFO A, DE BOER SF, BUWALDA B, KORTE-BOUWS G, TUMA J, BOHUS B, ZAAGSMA J, KOOLHAAS J: M. Vulnerability to arrhythmias during social stress in rats with different sympathovagal balance. Am J Physiol Heart Circ Physiol 275: H460-H466, 1998.

SKRZYPIEC-SPRING M, GROTTHUS B, SZELĄG A, SCHULZ R: Isolated heart perfusion according to Langendorff — still viable in the new millennium. J Pharmacol Toxicol Methods 55: 113-126, 2007.

SPEECHLY-DICK ME, MOCANU MM, YELLON DM: Protein kinase C. Its role in ischemic preconditioning in the rat. Circ Res 75: 586-590, 1994.

SUGIYAMA A, TAKAHARA A, HONSHO S, NAKAMURA Y, HASHIMOTO K: A simple in vivo atrial fibrillation model of rat induced by transesophageal atrial burst pacing. J Pharmacol Sci 98: 315-318, 2005.

WAGNER GS, MACFARLANE P, WELLENS H, JOSEPHSON M, GORGELS A, MIRVIS DM, PAHLM O,SURAWICZ B, KLIGFIELD P, CHILDERS R, GETTES LS, BAILEY JJ, DEAL BJ, GORGELS A, HANCOCK EW, KORS JA, MASON JW, OKIN P, RAUTAHARJU PM, VAN HERPEN G: AHA/ACCF/HRS recommendations for the standardization and interpretation of the electrocardiogram: part VI: acute ischemia/infarction: a scientific statement from the American Heart Association Electrocardiography and Arrhythmias Committee, Council on Clinical Cardiology; the American College of Cardiology Foundation; and the Heart Rhythm Society. Endorsed by the International Society for Computerized Electrocardiology. J Am Coll Cardiol 53: 1003-1011, 2009.

ZORNIAK M, MITRĘGA K, BIAŁKA S, PORC M, KRZEMIŃSKI TF: Comparison of thiopental, urethane, and pentobarbital in the study of experimental cardiology in rats in vivo. J Cardiovasc Pharmacol 56: 38-44, 2010. 